\title{
Metacognição, objetivos de leitura e atividades didáticas de língua portuguesa
}

Metacognition, Reading Goals and Didactic Activities of Portuguese as a Mother Tongue

Ana Flávia Lopes Magela Gerhardt*

Universidade Federal do Rio de Janeiro

Rio de Janeiro - Rio de Janeiro / Brasil

Patrícia Ferreira Botelho**

Universidade Federal do Rio de Janeiro

Rio de Janeiro - Rio de Janeiro / Brasil

Aline Mendes Amantes***

Universidade do Estado do Rio de Janeiro

Rio de Janeiro - Rio de Janeiro / Brasil

RESUMO: Muitas atividades de leitura de textos escritos nos livros didáticos de Português propõem apenas questôes de cópia-colagem de informaçōes explícitas dos textos, salientando somente uma parte do processo da leitura, não auxiliando na compreensão da leitura como ação cognitiva e metacognitiva, que requer definição de objetivos para ser realizada, e não auxiliando no processo de avaliação da qualidade da leitura dos alunos. Com base nas pesquisas em metacognição acerca dos objetivos de leitura, e por meio do exame de uma atividade retirada de livro didático, evidenciam-se causas e consequências do problema em foco. Propóe-se ainda uma atividade para avaliar a qualidade de leitura dos alunos, discutindo-se formas de ajudá-los a compreender o seu processo de leitura como uma ação também definida pelos objetivos de construção de significados a partir da leitura de um texto.

PALAVRAS-CHAVE: cognição; metacognição; objetivos de leitura; material didático de língua portuguesa; ensino de língua materna.

\footnotetext{
*portufrj@yahoo.com.br

** pattyfb@yahoo.com.br

*** aline.amantes@yahoo.com.br
} 


\begin{abstract}
Most reading activities presented in Portuguese as mother tongue course books propose only "copy-and-paste" questions of explicit information from texts, stressing only part of the entire cognitive process of reading. These activities do not help students understand reading as a cognitive and a metacognitive process which requires the establishment of reading goals; therefore they do not help students and teachers assess the students' reading quality. Based on research into metacognition and reading goals, and through observation of a students' book reading activity, this article highlights causes and consequences of the problem at issue. It also proposes an activity which aims to evaluate the students' reading quality and discusses how we can help them understand reading as an action also defined by the objectives for the construction of meaning from the reading of a given text.
\end{abstract}

KEYWORDS: cognition; metacognition; reading objectives; Portuguese teaching course books; Portuguese as mother tongue.

\title{
1. Introdução
}

Este artigo discute as atividades didáticas de leitura em Língua Portuguesa no Ensino Médio relativamente aos comportamentos cognitivos e às estratégias metacognitivas necessárias para a sua execução, considerando a proposição basilar da definição dos objetivos de leitura como um dos aspectos constitutivos da leitura de qualidade. O que motiva nossa discussão é a grande recorrência de questôes de cópia-colagem de informações explícitas ou sugeridas nos textos-base dessas atividades, conforme atestam pesquisas sobre o assunto (MARCUSCHI, 2001; BOTELHO, 2010; VARGAS, 2012).

Em termos de processamento cognitivo, tais atividades reconhecem apenas o processamento bottom-up (ascendente) de informação (McCLELLAND; RUMELHART, 1981), negligenciando o processamento top-down (descendente), relacionado à participação dos conhecimentos do leitor na construção dos significados em leitura. Em termos de estratégias metacognitivas, essas atividades não incluem a elaboração de hipóteses sobre os significados que os textos trazem, tampouco consideram a definição de objetivos de condução cognitiva para a execução das tarefas de leitura. Isso significa, entre outros problemas, que aos alunos não é dada a prerrogativa de gerenciar a construção de significados à medida que leem os textos, o que diminui consideravelmente a qualidade desse tipo de atividade (JOU e SPERB, 2003).

O procedimento dos livros didáticos está de acordo com a concepção de leitura apresentada em indicativos oficiais de ensino, como os descritores 
do MEC, por exemplo, que circunscrevem a leitura à detecção direta ou indireta de informações explícitas ou sugeridas no texto: "(i) localizar informaçóes explícitas em um texto; (ii) inferir o sentido de uma palavra ou expressão; (iii) inferir uma informação implícita em um texto; (iv) identificar o tema de um texto; (v) distinguir um fato da opinião relativa a esse fato" (BRASIL, 2011, p.22).

A leitura do mais recente Guia do Livro Didático do Ensino Médio (Brasil, 2012), por sua vez, permite inferir a mesma orientação bottom-up para a leitura observada nos descritores, agregada da ausência de discussão sobre metacognição e da não consideração da participação do aluno na construção dos significados no contato com o material escrito:

Há atividades voltadas diretamente para o desenvolvimento de capacidades implicadas na leitura proficiente, como o resgate de aspectos relevantes das condições de produção do texto, o reconhecimento do gênero e/ou do tipo de texto em jogo, a compreensão global, a localização de informações explícitas, a inferência de informações implícitas, a articulação entre diferentes partes do texto, a compreensão do sentido de vocábulos a partir de sua ocorrência em contextos determinados etc. (BRASIL, 2012, p.18)

Essas definições abarcam apenas o nível inicial e mais superficial de leitura (APPLEGATE e cols., 2002; VARGAS, 2012), não reconhecem a interação entre texto e leitor como uma competência básica essencial (conforme disposto em BRASIL, 2011) e excluem do processo a pessoa que lê. Essa prática contrapõe-se aos trabalhos sobre o estudo da leitura como ação cognitiva e metacognitiva (FULGÊNCIO e LIBERATO, 1992; SMITH, 1999 [1988]; APPLEGATE e cols., 2002; VARGAS, 2012, entre outros) e, não raro, produz a ideia de que existe apenas uma fonte de construção de significados em leitura: o texto em sua totalidade.

As duas coleções já sob a vigência do novo Guia do Livro Didático observadas por nós não agregam elementos para além dessa orientação, o que mostra que elas ainda não reconhecem a leitura como uma ação que envolve a participação ativa da pessoa que lê na construção dos significados. Uma delas, Abaurre, Abaurre e Pontara (2013) chega a incluir, em algumas atividades de leitura, ações metacognitivas como a definição de objetivos de leitura e a tarefa de formulação de hipóteses, mas de forma ainda muito tímida e nada sistemática, o que impede o aluno (e o professor também) de compreender que tais ações são parte constitutiva da leitura de qualidade. Mas a segunda, 
Faraco, Moura e Maruxo Jr. (2013), uma coleção bem conceituada pelos professores com quem dialogamos, sequer chega a isso, limitando-se ao recorte-colagem de informaçóes dos textos, com o acréscimo de questóes que nem precisam de aporte textual para serem respondidas. Sobre esses dados ainda vale a pesquisa realizada por Luiz Antônio Marcuschi, em 2001, que já registrava a presença massiva de questôes desses tipos nos livros didáticos, o que mostra que até o presente quase nada mudou no ensino de leitura no Brasil.

Neste artigo, entre as estratégias metacognitivas relevantes à leitura, focalizamos especificamente a definição de objetivos de leitura na relação entre autor e texto. $\mathrm{O}$ estabelecimento de objetivos de leitura refere-se à intervenção do leitor na seleção prévia de quais significados deverão ser capturados na interação com o texto, a partir de uma definição específica do que se quer reconhecer nele. Nessa perspectiva, como a noção de leitura proposta pelos livros didáticos não corresponde, de fato, a como o ser humano cogniza quando lê, assumimos como premissa que as atividades escolares, por não promoverem a leitura como ação cognitiva plena, não permitem a professores e alunos compreender as capacidades destes últimos como leitores, nem identificar eventuais dificuldades de leitura para saná-las em atividades posteriores.

Este artigo constrói-se a partir dos pressupostos teóricos e descritivos que nos permitem abordar essa premissa. Tais bases também subsidiam a formulação de alternativas às questões de cópia-colagem, para um melhor diagnóstico das habilidades e das dificuldades de leitura dos alunos, e para o oferecimento de subsídios para atividades de implementação de práticas necessárias à construção de uma leitura de qualidade.

Para tanto, apresentamos o modelo cópia-colagem que caracteriza a maioria das atividades de leitura nos livros didáticos. Posteriormente, tecemos comentários acerca dos conceitos e corolários relacionados à definição de objetivos de leitura, como parte do conjunto de estratégias metacognitivas concernentes à leitura de textos escritos. Por fim, discutimos os resultados de uma atividade de leitura elaborada com objetivos específicos, com base nos princípios recortados neste artigo: a avaliação da qualidade da leitura dos alunos, com reflexôes em prol de melhorias na execução dessa atividade escolar. 


\section{Atividades escolares de leitura: o modelo cópia-colagem}

O reconhecimento de informações na superfície do texto é uma ação cognitiva importante no processamento geral da leitura. Por isso, essa ação é aceitável em atividades escolares que tencionam levar os alunos a desenvolverem uma leitura aprofundada e uma melhor compreensão dos textos lidos. Não obstante, junto a esse tipo de exercício, outros níveis de leitura, como os que incluem inferências e interferências agentivas sobre o texto (APPLEGATE e cols., 2002; MENEGASSI, 1995; VARGAS, 2012), também devem ser contemplados. Por conseguinte, o fato de os livros didáticos de Língua Portuguesa oferecerem majoritariamente atividades de leitura no modelo cópia-colagem constitui uma falha metodológica grave, porque, dessa forma, eles impóem aos alunos a mera reprodução de informaçōes e tornam insuficiente a construção de significados durante a realização da atividade, o que pode ocasionar neles um entendimento equivocado sobre o que é ler e sobre quais são as suas reais capacidades como leitores.

Esses problemas são notados nas atividades a seguir, retiradas de Cereja e Magalhães (2010), cujo gabarito oferecido ao professor está em negrito.

\section{Texto I}

"Dali houvemos vista de homens que andavam pela praia, cerca de sete ou oito, segundo os navios pequenos disseram, porque chegaram primeiro. Ali lançamos os batéis e esquifes à água e vieram logo todos os capitães das naves a esta nau do Capitão-mor e ali conversaram. E o Capitão mandou no batel, se a terra, Nicolau Coelho para ver aquele rio; e quando começou a ir para lá acudiram, à praia, homens, aos dois e aos três. Assim, quando o batel chegou à foz do rio estavam ali dezoito ou vinte homens, pardos, todos nus, sem nenhuma roupa que lhes cobrisse suas vergonhas. Traziam arcos nas mãos e suas setas. Vinham todos rijos para o batel e Nicolau Coelho fez-lhes sinal para que deixassem os arcos e eles os pousaram. Mas não pôde ter deles fala nem entendimento que aproveitasse porque o mar quebrava na costa."

Batel e esquife: barcos pequenos.

Texto II

"Capitão, quando eles vieram, estava sentado em uma cadeira, com uma alcatifa aos pés, por estrado, e bem vestido com um colar de ouro muito grande ao pescoço [...] Acenderam-se tochas e entraram; e não fizeram nenhuma menção de cortesia nem de falar ao Capitão nem a ninguém. Mas um deles viu o colar do Capitão e começou a acenar com a mão para a terra e depois para o 
colar, como a dizer-nos que havia ouro em terra; e também viu um castiçal de prata e da mesma forma acenava para terra e para o castiçal como que havia, também, prata. Mostraram-lhe um papagaio pardo que o Capitão aqui traz; tomaram-no logo na mão e acenaram para terra, como que os havia ali; mostraram-lhe um carneiro e não fizeram caso dele; mostraram-lhe uma galinha e quase tiveram medo dela e não lhe queriam pôr a mão; e depois a pegaram como que espantados."

Alcatifa: tapete grande para revestir o chão.

\section{Texto III}

"De ponta a ponta é toda praia rasa, muito plana e bem formosa. Pelo sertão, pareceu-nos do mar muito grande, porque a estender a vista não podíamos ver senão terra e arvoredos, parecendo-nos terra muito longa. Nela, até agora, não pudemos saber que haja ouro nem prata, nem nenhuma coisa de metal, nem de ferro; nem as vimos. Mas, a terra em si é muito boa de ares, tão frios e temperados, como os de Entre-Douro e Minho, porque, neste tempo de agora, assim os achávamos como os de lá. Águas são muitas e infindas. De tal maneira é graciosa que, querendo aproveitá-la dar-se-á nela tudo por bem das águas que tem. Mas o melhor fruto que nela se pode fazer, me parece que será salvar esta gente; e esta deve ser a principal semente que Vossa Alteza nela deve lançar.” (In: Cronistas e viajantes. São Paulo: Abril Educação, 1982. p. 12-23. Literatura Comentada.)

Texto IV

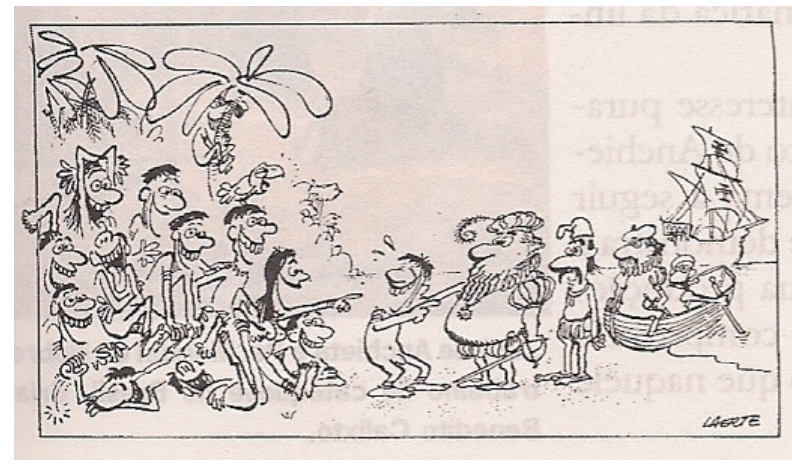

1. Segundo Pero Vaz de Caminha, Nicolau Coelho não conseguiu comunicar-se oralmente com os índios.

a) $\mathrm{O}$ que alegou como causa? $\mathrm{O}$ barulho das ondas do mar que rebentavam na costa.

b) Qual foi o verdadeiro motivo pelo qual a comunicação oral não se realizou? O fato de falarem línguas diferentes. 
2. Caminha descreve o primeiro encontro entre os índios e o capitão.

a) O que revela a postura do capitão? Que ele esperava, como capitão, ser reverenciado.

b) Qual foi a reação dos índios e o que ela revela? Os índios não lhe fizeram nenhuma mesura. As diferentes posturas revelam obviamente um choque cultural.

3. Quais eram as informações que os portugueses mais desejavam obter acerca da nova terra? Se havia ou não metais preciosos, como ouro, prata e ferro, na terra recém-descoberta.

4. Os portugueses não encontraram na terra recém-descoberta aquilo que mais lhes interessava. Identifique o que Caminha humildemente propõe ao monarca nos trechos:

a) "De tal maneira é graciosa que, querendo aproveitá-la dar-se-á nela tudo por bem das águas que tem.” Que a terra seja colonizada.

b) "Mas o melhor fruto que nela se pode fazer, me parece que será salvar esta gente." A catequização dos índios, de acordo com o ideal português de propagação da fé.

5. Aponte semelhanças entre os textos acima e esses versos de Camões, quanto ao ponto de vista do colonizador português sobre os motivos da colonização:

E também as memórias gloriosas

"Daqueles Reis que foram dilatando

A Fé, o Império, e as terras viciosas

De África e de Ásia andaram devastando,”

Tanto no texto de Caminha quanto nesse fragmento de Os Lusíadas, de Camões, os interesses econômicos e políticos do imperialismo português são justificados com o argumento de que é necessário levar o cristianismo às "terras viciosas" (não cristãs).

6. Os textos de Caminha são escritos pela ótica do colonizador. Compare o texto I ao texto IV:

a) O cartum de Laerte traduz uma visão do colonizador ou do colonizado? Por quê? Uma visão do colonizado; porque são os índios que fazem um julgamento dos portugueses.

b) Na sua opinião, por que os índios estão rindo? Resposta pessoal. Sugestão: talvez da roupa ou dos modos dos portugueses. Professor: chame a atenção do aluno para o fato de que o humor desse cartum reside justamente nessa inversão de perspectivas.

CEREJA, W. R. e MAGALHÃES, T. C. Português: linguagens - literatura, produção de texto, gramática. Ensino Médio. 7a ed. São Paulo: Atual Editora, 2010, p.175-176. 
Uma primeira observação importante refere-se à ausência de objetivos para essa atividade, o que já representa uma artificialidade. Sem isso, não é possível estabelecer quais significados a atividade pretende fazer emergir. Além disso, a própria tarefa, ao não apresentar objetivos, não tem qualquer razão para existir, embora o contraste entre os textos de Pero Vaz de Caminha e de Laerte Coutinho seja tão oportuno e apropriado, e com pelo menos uma potencial leitura claramente disponível para análise e reflexão: a comparação entre visões antigas e atuais acerca do descobrimento do Brasil. Lamentavelmente, os exercícios esvaziam a possibilidade de diálogo entre os alunos e os textos dados, porque, entre outras razões, não motivam a pensar de forma crítica sobre o primeiro encontro entre portugueses e índios em terras brasileiras.

Além disso, ou talvez em função disso, os alunos apenas começam a responder às questôes dessa atividade depois de lerem todos os textos, o que evidencia o descomprometimento do exercício com a checagem entre o que os alunos estão lendo e as expectativas de leitura que eles possam ter construído previamente, o que impede uma aferição da qualidade de leitura, inclusive em termos das inferências que eles constroem. Assim, eventuais desvios dos objetivos de leitura não podem ser detectados, e compreensões não legitimadas pelos textos não podem ser reencaminhadas.

A atividade como um todo não explora a participação dos alunos na leitura do texto: poucas questões solicitam que eles, de alguma forma, invistam pensamentos próprios e não reproduzidos do texto especificamente, as perguntas 4 e 6 . Ainda assim, esse investimento não diz respeito explicitamente àquilo que os alunos já sabem sobre a descoberta do Brasil para que isso seja articulado aos dados do texto: as perguntas mais se parecem com algo como "o que o autor quis dizer" do que propriamente com um convite ao julgamento sobre o que de fato está sendo lido.

No mais, a maioria das perguntas da atividade reitera a prática descrita neste artigo: a mera cópia-colagem de informaçôes explícitas e sugeridas no texto, que não são, sob nenhuma hipótese, desafiadoras para os alunos, porque não requerem que eles busquem respostas articulando as informaçôes do texto aos seus projetos de leitura, nem os levam a utilizar qualquer estratégia de busca agentiva de informação além do rastreamento de informações do texto.

Tarefas desse tipo incapacitam os alunos para ler com qualidade os textos que lhes são apresentados não apenas na escola, mas também fora 
dela. Entretanto, pelo fato de se repetirem à exaustão nos livros didáticos de Língua Portuguesa e de outras Disciplinas, como, por exemplo, História (BOTELHO, 2010), tais tarefas acabam tornando-se o modelo do que é a leitura não apenas para os alunos, mas também para os demais agentes escolares, incluindo o professor. Os alunos realizam as atividades na certeza de que, na avaliação, encontrarão o mesmo tipo de questão, que suscitará deles o mesmo tipo de ação cognitiva. Não é sem razão, portanto, que eles, em sua maioria, não têm prazer em ler e realizam as atividades apenas para compreender como serão as questôes das provas a que serão submetidos.

A supressão dos planejamentos e das buscas individuais de leitura operada pelas tarefas de cópia-colagem resolve o problema da variabilidade das respostas e de compreensões difíceis de mensurar, controlar e avaliar, supostamente causadas pelas tarefas que estimulam a agentividade metacognitiva. Tornar o texto fonte única de informação, por meio de atividades de leitura limitadas à cópia-colagem, é a solução ideal para produzir metodologias de avaliação que recolhem respostas absolutas, mais aptas, portanto, à quantificação e à obtenção de resultados de avaliação. No entanto, não se deve esperar que essas tarefas possam trazer aprendizados de qualidade, seja quanto ao conteúdo, seja quanto à autonomia dos alunos como leitores.

A ausência dos saberes dos alunos na estruturação das atividades escolares, consubstanciada, nas atividades de leitura, pela não construção de objetivos para que eles leiam determinados textos, provém, em última instância, do pensamento de que o que os alunos já conhecem não precisa ser incluído nas atividades, já que estas se propõem a ensinar apenas o que eles supostamente não sabem. Tal pensamento não identifica os saberes prévios dos alunos como parte da construção do aprendizado e não problematiza o aspecto processual e, por isso, a cada vez sempre único, da relação entre texto e leitor. Em decorrência disso, não reconhece que a mera repetição de informações explícitas do texto não produz aprendizado, e, quando esse problema é considerado, não se consegue definir as suas causas profundas.

Como parte do projeto de construção da leitura de qualidade na escola, deve-se iniciar definindo que ler é uma ação basicamente constituída da articulação de conhecimentos entre texto e leitor, condicionada por, entre outras estratégias metacognitivas, o estabelecimento de objetivos de leitura. Discutiremos esse tema na próxima seção, a fim de propor atividades que sejam mais próximas das plenas ações cognitivas que compõem o processo de ler. 


\section{O estabelecimento de objetivos de leitura na construção de uma atitude metacognitiva}

Todas as açôes cognitivas, por serem dinâmicas, requerem objetivos para serem executadas e ajuste de procedimentos relativos às condiçôes específicas do trato com um dado conhecimento (TARRICONE, 2011), compondo-se de estratégias que visam a fins também específicos. Congruentemente, a literatura sobre a definição de objetivos de leitura reconhece que, a partir dos mesmos dados dispostos em um texto, podese chegar, tendo em vista diferentes objetivos de leitura, a diferentes representações mentais e a diferentes inferências preditivas e retrospectivas sobre esse texto (ISHIWA e cols., 2013), daí a necessidade de refletir acerca do estabelecimento de objetivos para a própria elaboração de atividades de leitura, discutindo teórica e metodologicamente os materiais didáticos de Língua Portuguesa, principalmente no que se refere à avaliação da qualidade da leitura que os alunos realizam.

Os estudos em metacognição asseveram que qualquer pessoa, ao cumprir uma tarefa, não apenas age cognitivamente, mas também traça, em sua mente, um plano de conhecimento das estratégias que emprega para chegar à solução pretendida e poder relacionar essas ações a necessidades futuras. Nesse sentido, em relação ao problema central deste artigo, a própria atividade de leitura, a partir do reconhecimento de como funciona a mente dos alunos diante de tarefas desse tipo, precisa explicitar um plano de leitura adequado ao texto em questão, para ajudá-los não apenas a cognizarem agentivamente em sala de aula, mas também a reconhecerem suas próprias capacidades e limitações relacionadas a um determinado conteúdo. Tais ações têm por propósito o desenvolvimento e o refinamento de uma atitude pessoal, por parte dos alunos, de definirem, eles mesmos, os seus objetivos para ler qualquer texto e realizar quaisquer outras açôes cognitivas.

Por isso, na elaboração das atividades de leitura, é preciso, entre outros procedimentos importantes, estabelecer para os alunos objetivos para ler um texto e auxiliá-los a mantê-los em mente durante a atividade, para que a seleção de conteúdos abstraídos por eles tenha consistência e organicidade, e possa proporcionar aprendizado de conceitos. A formulação desses objetivos deve ser realizada com o pleno conhecimento, por parte dos alunos, de suas fontes de aquisição de informaçôes; e, se for cotidianamente empregada na escola para atividades de leitura, pode ajudar a compor um conjunto amplo de subsídios para a administração de ações cognitivas em geral, 
relacionadas a ações futuras - por exemplo, para avaliações mais imediatas, e também para as que se situam num âmbito institucional mais amplo, em que provavelmente se replicarão as ações que eles aprendem na escola. Essas propriedades reforçam ainda mais a necessidade de que os estudos em metacognição passem a participar da organização dos materiais didáticos que incluam atividades de leitura, não apenas em Língua Portuguesa, mas em todas as Disciplinas em que ler é uma prática essencial para o aprendizado (BOTELHO, 2010).

Tais reflexões são, a nosso ver, cruciais para um re-entendimento do que seja um ensino de qualidade, o qual, para o pesquisador em cognição e ensino, inclui promover o agenciamento dos alunos sobre seus próprios processos de aprendizado. Esse agenciamento, atrelado ao autoconhecimento que a utilização sistemática e consciente das estratégias metacognitivas traz, propicia o desenvolvimento de uma atitude metacognitiva (CORNOLDI, 1998), atividade mental de alto nível, por isso mesmo fundamental para as ações cognitivas autônomas por parte das pessoas.

A literatura que discute a formulação de atividades de leitura com objetivos claros para o que vai ser lido apresenta as significativas vantagens dessa opção para o desenvolvimento dos alunos como leitores autônomos:

(i) Ajuda a recuperar, durante a leitura, não apenas o contexto mais amplo em que o texto se insere, mas também a sua coerência interna (JOU; SPERB, 2003; GEIGER; MILLIS, 2004);

(ii) Ajuda a definir de partida quais serão as prováveis dificuldades de leitura a serem enfrentadas no trato com um texto em específico, o que é fundamental na elaboração de atividades didáticas que ajudem a sanar esses obstáculos, entre outras finalidades (ISHIWA e cols., 2013);

(iii) Ajuda na maior e melhor formulação de inferências sobre o texto, bem como na recuperação das informaçôes lidas, a qual varia de acordo com as formas de engajamento situado entre textos e leitores (VAN DEN BROECK e cols., 2001);

(iv) E, sendo a leitura uma ação motivada por excelência, o estabelecimento de objetivos de leitura se torna uma motivação para a pessoa se engajar na tarefa de buscar compreensões, articulações e inferências durante a sua atividade (RE, 2008); o sucesso nessa iniciativa favorece a que ela se proponha espontaneamente a realizar novas tarefas, em novas ocasióes. 
Deve-se salientar que o ensino-aprendizado sistematizado da ação de estabelecer objetivos de leitura é uma tarefa realizada primordialmente no ambiente escolar, já que, em função de ser uma atividade metacognitiva, necessita de um trabalho didático - especificamente, um trabalho de meta-aprendizado -, para que seja incorporada às atividades cotidianas de leitura da pessoa. Sem esse trabalho, pelo menos dois problemas podem aparecer: a leitura sem nenhum objetivo estabelecido, que não traz qualquer gerenciamento em termos de ações de interpretação tampouco qualquer possibilidade de aprendizado; a leitura com objetivos que não correspondem à natureza do texto e à situação/contexto em que ele é lido (SWAIN, 2005). Cabe ao pesquisador em leitura ter essas ideias em mente ao propor atividades nas variadas Disciplinas escolares em que a leitura de textos de diversos gêneros seja uma ação importante de aprendizado.

Para refletirmos sobre um padrão de atividades de leitura e os requisitos necessários ao seu ensino, reconhecendo que o andamento da leitura dos textos está diretamente relacionado às instruções e motivações dadas aos alunos (VAN DEN BROECK e cols., 2001, p.1082), presumimos que uma boa tarefa será aquela que, entre outras açôes, saberá definir propósitos claros para a leitura de um texto, ativando conhecimentos prévios dos alunos e atrelandos-o aos saberes explorados nos textos do livro didático (GERHARDT, 2009). Além disso, a atividade deve ser capaz de permitir ao professor avaliar o modo como os alunos se comportam cognitivamente quando leem, em vias da construção de uma atitude mais autônoma diante das tarefas que lhes são propostas, o que lhes trará ganhos significativos em termos de aprendizado escolar.

\subsection{A atividade de leitura: o modelo das três etapas}

Com base nos propósitos enunciados acima, apresentamos uma atividade de leitura desenvolvida a partir das bases fornecidas por Nelson e Narens $(1990,1994)$, que definem três etapas na elaboração e resolução de tarefas de leitura - tarefas de aquisição de informações, de retenção de informações e de recuperação de informações, resumidas abaixo:

(i) As tarefas do estágio de aquisição incluem o recrutamento de dados do objeto de estudo para a checagem das estratégias utilizadas - no caso, o enquadramento, na memória rasa, de conhecimentos prévios que são importantes para uma boa leitura do texto. 
(ii) No estágio de retenção, administra-se a coleta e a manutenção do aprendizado do objeto de estudo, em relação aos conhecimentos prévios levantados e aos objetivos de leitura.

(iii) O estágio final de recuperação contém atividades de fixação e verificação da aprendizagem e de checagem do alcance dos objetivos de leitura. Nesse estágio, é possível refletir sobre a relação entre os dados recrutados e os conhecimentos prévios dos alunos, em vias de validar as informações capturadas durante a leitura.

A utilização da proposta de Nelson e Narens se insere numa perspectiva de ensino que busca não apenas avaliar a leitura dos alunos, mas também facultar o desenvolvimento da sua capacidade de criar estratégias próprias de leitura através da articulação entre as informações do texto e os conhecimentos que eles trazem como contribuição para a leitura. Tais ações, se tornadas cotidianas, permitirão aos alunos administrar autonomamente seus processos de leitura a partir das estratégias aprendidas por meio das atividades.

Nossa atividade constrói-se sobre os mesmos textos que fundamentaram a tarefa de Cereja e Magalhães (2010); entretanto, elaboramo-la a fim de valorizar o potencial de construção de significados e de estabelecimento de pontes para novos conhecimentos que o trabalho com os diferentes textos propostos pelo livro pode proporcionar, mas que não foram explorados por seus autores. O objetivo da leitura, que, a propósito, emerge diretamente dos textos escolhidos, é o de estabelecer articulaçôes e comparações entre dados do passado e do presente na História do Brasil, com a detecção de fatos ou comportamentos sociais que representam mudanças e permanências - aliás, uma questão central no ensino contemporâneo de História. Esse objetivo é explicitado aos alunos, mantido ao longo da atividade e utilizado para nortear a elaboração das perguntas. As questões da etapa que estamos denominando atividades de pré-leitura (uso deste e dos outros termos abaixo para o ensino de português em AMANTES, BOTELHO, 2011) pretendem ativar o conhecimento prévio dos alunos a respeito do descobrimento do Brasil, para que eles postulem hipóteses e realizem articulações entre o que já sabem sobre o assunto e o que os textos têm a oferecer. Isso permitirá aos alunos agregar novas informações, de preferência informações críticas, ao seu conhecimento de mundo.

As questôes apresentadas na etapa de retenção, denominadas atividades durante a leitura, realizadas no intervalo entre os textos, buscam estabelecer 
vínculos entre passado e presente na História do Brasil, em termos de relações étnicas e de percepção sobre as riquezas brasileiras. Embora haja perguntas de cópia-colagem, elas são elaboradas com a finalidade de reforçar a problematização passado-presente, relativizando as interpretações acerca da comunicação entre europeus e índios à época do descobrimento do Brasil, a fim de ajudar os alunos a compreender que as ideias de um grupo étnico ou social em relação a outros mudam ao longo do tempo, e com isso mudam os valores e as crenças, e que um pensamento não pode ser discutido fora do seu contexto de vigência, validação e legitimidade.

As questões que finalizam a tarefa, intituladas atividades de pósleitura, realizadas na etapa de recuperação, buscam ir além dos textos, para sedimentar nos alunos a percepção crítica motivada durante as etapas de pré-leitura e durante a leitura. Observe-se, porém, que essa percepção é realizada sem se perder de vista o objetivo de leitura que foi inicialmente posto, e também com o apoio dos textos-base, que são lembrados nas questões não apenas como ponto de partida para as respostas, mas também como critérios e perspectivas de encaminhamento das respostas. Com isso, pudemos construir atividades que são inequivocamente de leitura e de construção de significado e que contam com a parceria entre o conhecimento prévio dos alunos e a informação dos textos, mantendo, mesmo assim, a objetividade que as atividades de cópia-colagem parecem ter, mas sem permitir uma avaliação de leitura fidedigna dos textos nem resultar em leitura de qualidade.

De acordo com as observaçóes feitas acima, seguem abaixo as atividades de leitura relacionadas aos textos de Pero Vaz de Caminha e de Laerte Coutinho.

\section{Pré-leitura}

Uma boa reflexão sobre textos que relatam acontecimentos históricos dizem respeito a um contraste entre fatos passados e a atualidade, levando em conta as diferenças de comportamento, ideias, culturas, sociedades, entre tempos passados e atuais. Essa reflexão é importante por dois motivos: primeiro, elas nos ajudam a reconhecer a evolução das civilizações e a compreender que não podemos avaliar tempos passados pelos mesmos parâmetros que usamos para avaliar tempos atuais; segundo, a partir desse contraste, também podemos reconhecer que muitas mudanças são apenas aparentes, e que muitas percepçôes e ideologias mantiveram-se ao longo do tempo. Procure realizar todas as atividades de leitura propostas a seguir com foco nas ideias colocadas acima. 
1) O que você conhece acerca do descobrimento do Brasil (1500)?

2) O que você imagina que sejam as cartas de Pero Vaz de Caminha?

3) Explique, em breves palavras, por que Pero Vaz de Caminha escreveu essas cartas.

4) Explique, em breves palavras, que imagem se construiu sobre os índios e os portugueses nos textos de história que relatam a chegada dos portugueses ao Brasil.

\section{Durante a leitura}

\section{Texto I}

"Dali houvemos vista de homens que andavam pela praia, cerca de sete ou oito, segundo os navios pequenos disseram, porque chegaram primeiro. Ali lançamos os batéis e esquifes à água e vieram logo todos os capitães das naves a esta nau do Capitão-mor e ali conversaram. E o Capitão mandou no batel, à terra, Nicolau Coelho para ver aquele rio; e quando começou a ir para lá acudiram, à praia, homens, aos dois e aos três. Assim, quando o batel chegou à foz do rio estavam ali dezoito ou vinte homens, pardos, todos nus, sem nenhuma roupa que lhes cobrisse suas vergonhas. Traziam arcos nas mãos e suas setas. Vinham todos rijos para o batel e Nicolau Coelho fez-lhes sinal para que deixassem os arcos e eles os pousaram. Mas não pôde ter deles fala nem entendimento que aproveitasse porque o mar quebrava na costa."

Batel e esquife: barcos pequenos.

1) No texto I, Pero Vaz de Caminha descreveu os índios que encontrou na praia brasileira, após atracar a nau portuguesa.

Como os índios foram descritos?

Atualmente, os índios seriam descritos dessa forma? Por quê?

Se a sua resposta à questão $\mathrm{b}$ for negativa, procure explicar o que pode ter alterado a visão que temos sobre os índios ao longo da nossa história.

\section{Texto II}

"Capitão, quando eles vieram, estava sentado em uma cadeira, com uma alcatifa aos pés, por estrado, e bem vestido com um colar de ouro muito grande ao pescoço [...] Acenderam-se tochas e entraram; e não fizeram nenhuma menção de cortesia nem de falar ao Capitão nem a ninguém. Mas um deles viu o colar do Capitão e começou a acenar com a mão para a terra e depois para o colar, como a dizer-nos que havia ouro em terra; e também viu um castiçal de prata e da mesma forma acenava para terra e para o castiçal como que havia, também, prata. Mostraram-lhe um papagaio pardo que o Capitão aqui traz; tomaram-no logo na mão e acenaram para terra, como que os havia ali; mostraram-lhe um carneiro e não fizeram caso dele; mostraram-lhe uma galinha e quase tiveram medo dela e não lhe queriam pôr a mão; e depois a pegaram como que espantados." Alcatifa: tapete grande para revestir o chão. 
2) No texto 2, percebemos que os portugueses e os índios tentaram interagir e comunicarse por meio de gestos. Sabendo que o texto trata de dois povos tão diferentes, responda: O relato de Caminha acerca da interpretação dos portugueses para o gesto de apontar dos índios pode ser considerado coerente com o que os índios pretendiam comunicar? Por quê? Você acha que, hoje em dia, os povos indígenas remanescentes do Brasil e os descendentes dos portugueses se comunicam melhor do que se comunicavam à época do descobrimento? Por quê?

\section{Texto III}

"De ponta a ponta é toda praia rasa, muito plana e bem formosa. Pelo sertão, pareceu-nos do mar muito grande, porque a estender a vista não podíamos ver senão terra e arvoredos, parecendo-nos terra muito longa. Nela, até agora, não pudemos saber que haja ouro nem prata, nem nenhuma coisa de metal, nem de ferro; nem as vimos. Mas, a terra em si é muito boa de ares, tão frios e temperados, como os de Entre-Douro e Minho, porque, neste tempo de agora, assim os achávamos como os de lá. Águas são muitas e infindas. De tal maneira é graciosa que, querendo aproveitá-la dar-se-á nela tudo por bem das águas que tem. Mas o melhor fruto que nela se pode fazer, me parece que será salvar esta gente; e esta deve ser a principal semente que Vossa Alteza nela deve lançar.” (In: Cronistas e viajantes. São Paulo: Abril Educação, 1982. p. 12-23. Literatura Comentada.)

3) No texto III, Pero Vaz de Caminha descreve as riquezas da terra brasileira que eles haviam acabado de descobrir. a. Segundo o texto, quais eram as riquezas brasileiras que os portugueses buscavam na época do descobrimento?

b. Estabeleça uma comparação entre essas "riquezas" da época do descobrimento e as atuais "riquezas" que o Brasil tem a oferecer.

Texto IV

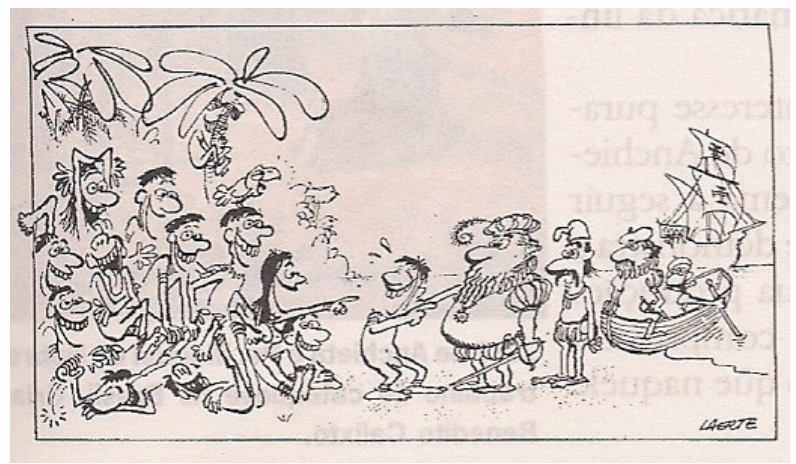

4) No texto 4, o cartunista Laerte apresenta a cena em que os portugueses encontram os índios quando do descobrimento do Brasil. Em que esse texto se diferencia dos demais textos lidos, em termos de forma e conteúdo? 


\section{Pós-leitura}

1) Desde a época da colonização, existe o convívio de diferentes etnias no território brasileiro. Tendo isso em vista e com base nos textos lidos, compare como essa relação foi construída no século XVI e como ela se constrói atualmente no século XXI. Elabore e justifique sua resposta tomando em conta a distribuição de riquezas e as formas como os diferentes grupos étnicos no Brasil se comunicam (ou não). 2) No texto 4, o cartunista Laerte apresenta uma crítica às descrições realizadas por Pero Vaz de Caminha acerca das primeiras impressões dos portugueses quando do descobrimento do Brasil. A visão de Laerte é coerente com a maneira como a sociedade atual percebe esse fato histórico? Justifique.

3) Com base no que você leu nos trechos da carta de Pero Vaz de Caminha, estabeleça uma comparação entre a visão desse autor e a visão de Laerte, no texto IV, sobre a colonização do Brasil, considerando o gesto de apontar dos índios, relatado nos textos II e IV.

A atividade que elaboramos foi aplicada para 45 alunos de uma turma de Ensino Médio de uma Escola Estadual do Município de Volta Redonda, RJ, de acordo com o volume do livro didático em que os textos se encontram: primeiro ano. Na Escola por nós escolhida, a coleção de Cereja e Magalhães tem sido regularmente adotada; a fim de não afetar a dinâmica das aulas, e também porque pretendemos checar como a atividade em si pode auxiliar na avaliação da qualidade de leitura dos alunos, apenas solicitamos ao professor que substituísse a atividade proposta pelo livro, no momento em que ela seria aplicada, pela outra que elaboramos.

Organizamos a análise dessa atividade e a discussão dos dados, assumindo a perspectiva de ação proposta neste artigo, a saber, a possibilidade de avaliação da qualidade da leitura dos alunos, com o apoio de uma atividade com objetivos explícitos. Para isso, consideramos como parâmetros as seguintes questões: em que medida os alunos acessaram conhecimentos prévios relevantes à definição dos objetivos de leitura do texto; se as respostas apresentadas fogem ou não ao padrão cópia-colagem dos livros didáticos; se a reflexão acerca do contraste temporal época do descobrimento $\mathrm{X}$ época atual relaciona-se ao objetivo de leitura dos textos que propusemos e às atividades propostas; e se será possível aos alunos construírem eventuais inferências a partir da integração entre seu conhecimento prévio e os dados dos textos. Apresentamos, a seguir, algumas de suas respostas tendo em vista as limitações de espaço deste artigo.

Atividades de pré-leitura: ao realizar essas atividades, quase todos os alunos acessaram, sem problemas, conhecimentos prévios que, em geral, foram congruentes com o tema dos textos - observem-se como evidências disso as respostas dos alunos 1 e 2 : 
Aluno 1:

1)Informações que sei sobre o desenvolvimento do Brasil, é que a tripulação portuguesa, junto a Pedro Alvares Cabral, estava indo em direção às Índias, mas desviaram o caminho e, por engano, descobriram o Brasil.

2) As cartas de Caminha eram úteis para manter Portugal informada sobre a viagem e como era o lugar que eles haviam acabado de descobrir.

3) Caminha escreveu cartas para avisar como era a viagem deles em direção às Índias, e com esse ocorrido, esse meio de comunicação oficializou a notícia de descoberta do Brasil.

4) As navegações da tripulação portuguesa foram desviadas para o Brasil, e aqui eles descobriram o pau-brasil, e devastaram a terra, enviando a madeira para os portugueses. Isso com a mão de obra dos índios, que trabalhavam em troca de objetos que os portugueses não tinham.

\section{Aluno 2:}

1) No dia 22 de abril de 1500, chegou Pedro Alvares Cabral que, no primeiro momento, achou que o Brasil era uma Grande Ilha e a chamou de Ilha de Vera Cruz. Conforme o tempo foi passando, eles perceberam que aqui havia uma grande quantidade de pau-brasil e que com essa árvore daria para fazer várias coisas, e por causa dessa árvore surge o nome do nosso país.

2) Eram cartas que eles escreviam e mandavam para Portugal sobre o descobrimento do Brasil, de tudo que havia aqui e sobre suas colônias.

3) Ele escreveu essas cartas, relatando que tinham descoberto as riquezas que havia aqui, para que o rei ficasse informado das coisas que estavam acontecendo no Brasil.

4) A imagem que se construiu foi que os índios eram negros, nus e sem muita inteligência, já os portugueses eram brancos, ricos, muito bem vestidos e achavam que podiam explorar os índios só porque tinham um poder maior.

Atividades durante a leitura: nesse momento da atividade, foi possível perceber que, mediante os parâmetros que estabelecemos para a análise das suas respostas, o comportamento cognitivo dos alunos evidenciou: a incidência de respostas cópia-colagem, a adequação de suas respostas aos objetivos de leitura e a provável formulação de inferências.

Quanto às respostas cópia-colagem, apenas a questão 1a se encaixa nesse padrão, e os alunos, em sua quase totalidade, não apenas repetiram dados, mas os transcreveram nas palavras do texto: "homens pardos, nus, sem 
nenhuma roupa que lhes cobrisse suas vergonhas", com mais ou menos dados também retirados do texto. O interessante a notar é que esse comportamento não se repetiu nas outras perguntas durante a leitura, em que os alunos utilizaram suas próprias ideias para responder o que estava proposto, sem recorrer às do texto; isso indica uma relativa independência em relação à formatação imposta pelos livros didáticos.

Quanto à adequação das suas respostas aos objetivos de leitura dos textos, em geral, as comparações entre a época do descobrimento do Brasil e os dias atuais foram feitas de forma congruente, tendo em vista as relaçóes entre os conhecimentos prévios dos alunos e os dados do texto. O mesmo se pode dizer em relação às novas informações que os alunos forneceram sobre $o$ Brasil atual: as respostas sobre as condiçôes atuais de vida dos índios brasileiros estão de acordo com os dados correntes; o mesmo ocorre em relação às riquezas naturais de que o Brasil dispóe. $\mathrm{O}$ aspecto mais interessante a ser abordado é a forma como alguns alunos enquadraram as diferenças históricas entre passado e presente: mudanças não na língua, nas pessoas ou nos elementos sociais, mas sim na forma com que as enxergamos atualmente, que não se assemelha a como fazíamos antes. Vejamos em detalhes esse dado:

1. Para responder à questão $1 \mathrm{c}$, diferentemente da maioria dos alunos, que apontaram mudanças no comportamento dos índios, 14 alunos afirmaram que, ao longo da história, a nossa visão sobre eles é que mudou. Vejam-se abaixo algumas respostas:

Aluno 16: A visão dos índios foi alterada porque hoje conhecemos mais sua cultura e sabemos que não existem culturas atrasadas ou culturas evoluídas, e sim culturas distintas, que têm o mesmo significado para seu povo, e por isso os respeitamos mais.

Aluno 18: porque antigamente os índios eram vistos como um povo primitivo, onde não tinham educação, cultura e eram agressivos, perigosos; hoje em dia com as leis e a educação já se tem outra visão dos índios.

Aluno 44: $\mathrm{O}$ que alterou a nossa visão ao longo da história sobre os índios foi o papel importante que eles tiveram para o nosso país, hoje vemos os índios como parte da nossa cultura, e não como um simples ser, que não era civilizado.

Aluno 45: Hoje, vemos os índios como pessoas que transformaram a nossa cultura, e a maioria das pessoas respeitam os costumes e crenças indígenas. 
2. Para responder à questão $2 \mathrm{~b}$, a perspectiva adotada pela maioria dos alunos para definir a qualidade do contato entre índios e não índios foi a de comunicação como código, mas oito alunos definiram comunicação como uma forma de significação social, que mudou com o tempo. Exemplos:

Aluno 06: Sim, porque, sob influência da colonização, os índios tiveram suas culturas arrancadas e impostas a do colono, o que influenciou a linguagem e o modo de vida dos índios.

Aluno 07: Atualmente eles se comunicam melhor por haver já um conhecimento maior sobre as duas culturas, ou seja, sim.

Aluno 15: Sim, através da convivência, o homem aperfeiçoa sua comunicação, ou seja, quanto mais conversam, mais se entendem.

Aluno 21: Sim, porque, com a influência da colonização, foi gerada uma nova nação com seus costumes, cultura e língua, portanto, a forma de comunicação se tornou mais ampla e fácil através da linguagem, não de gestos.

3. Para responder à questão $3 \mathrm{~b}$, a grande maioria dos alunos afirmou que, ao longo do tempo, as riquezas é que mudaram, ou diminuíram, mas quatro alunos afirmaram que nossa visão do que é riqueza e de como lidar com ela é que mudou, com base em diferentes perspectivas e interesses:

Aluno 09: As riquezas do Brasil continuam as mesmas, o foco sobre ela é que mudou. Pela extensão do país cada região explora mais o que lhe convém.

Aluno 30: Antigamente as consideradas riquezas eram ouro e prata e hoje a Amazônia é a maior riqueza, os homens procuram ganhar em cima do que dá dinheiro, não necessariamente do ouro.

Aluno 35: Atualmentem as riquezas brasileiras não são as mesmas. Tudo se baseia nas economias, não nas riquezas minerais.

Aluno 38: As riquezas da época do descobrimento não são as mesmas riquezas da nossa atualidade. Antes, valorizavam-se o ouro e a prata e, hoje em dia, são valorizadas as terras férteis, até mesmo porque não há muito de ouro e de prata para se explorar.

A construção de diferentes perspectivas a partir de um mesmo objetivo de leitura é um dado suficientemente interessante para motivar um possível 
debate acerca dos contrastes entre os textos, bem como as transformações ao longo da nossa história, definindo relações de causa-consequência entre mudanças de pensamento e alteraçóes sociais e econômicas. Além de um debate, textos também podem ser produzidos problematizando não apenas as transformações na nossa sociedade, mas a forma como lidamos com elas. De todo modo, o importante é reparar que tais significados, não previstos por nós na elaboração da atividade, mas perfeitamente congruentes com os objetivos postos na sua elaboração, emergiram das ações cognitivas pessoais dos alunos, e não teriam sido construídos, tampouco identificados, numa tarefa de leitura baseada em cópia-colagem de informações.

Quanto à formulação de inferências, elas não ocorreram em quantidade, mas é importante sinalizá-las, já que sempre representam interferências agentivas importantes sobre o material textual lido. Elas ocorreram em respostas à questão $2 \mathrm{a}$, em que dois alunos reconheceram que os índios não conheciam alguns dos animais trazidos pelos portugueses, e dois julgaram que os portugueses podem ter interpretado equivocadamente os gestos dos índios:

Aluno 03: Sim. Dava para perceber no momento em que eles estranharam a galinha e o carneiro. Eram animais com que eles nunca haviam tido contato. Já o papagaio eles não estranharam e apontaram para terra como sinal de que já tinham o visto.

Aluno 04: Sim, pois a galinha e o carneiro eles não conheciam nem nunca tinham visto, já o papagaio eles conheciam.

Aluno 06: Porque nem sempre a interpretação dos portugueses era que os índios queriam comunicar-se.

Aluno 27: Não, pois os portugueses não conheciam a realidade nem a linguagem dos índios, desse modo não poderiam interpretar os gestos deles como bem entendessem.

Já afirmamos que um dado importante a este artigo é a possibilidade de que as atividades com claros objetivos de leitura façam emergir problemas entre os alunos na sua reflexão e elaboração de respostas, algo que atividades de cópia-colagem não podem detectar. No caso da nossa atividade, isso realmente aconteceu: especificamente, o principal problema foi o de formulação de inferências não autorizadas pelos textos, isto é, inferências que não encontram nos dados do texto qualquer informação que lhes 
permita serem formuladas (Vargas, 2012). Este tipo de problema ocorreu, principalmente, em quatro respostas à questão 2a: dois alunos afirmaram que os índios tiveram medo dos portugueses; um aluno afirmou que os portugueses é que estavam receosos; e um aluno relacionou os gestos dos índios a uma possível crença deles:

Aluno 07: Sim, pois ali realmente havia ouro, porém eles ficaram com medo.

Aluno 12: Não, porque eles tiveram medo.

Aluno 30: Os portugueses tiveram medo, pois desconheciam a cultura dos índios.

Aluno 19: Não, porque os portugueses não conheciam esse povo, e aquilo poderia ser algo religioso...

Cinco inferências não autorizadas pelo texto foram identificadas nas respostas à questão 4: cinco alunos afirmaram que o contraste entre os textos de Pero Vaz de Caminha e o do cartunista Laerte Coutinho resumia-se a uma troca de papéis: Para Caminha, os portugueses riram dos índios; para Laerte, os índios é que riem dos portugueses. Ora, muito embora no segundo caso isso seja verdade, não há qualquer menção a gracejo ou deboche aos índios na carta de Caminha, o que torna a inferência problemática.

Aluno 01: Se diferencia no aspecto de que as diferenças existentes entre os índios e os portugueses fazem com que os índios "cassoem" da imagem que eles passavam, como se os índios não fossem como o que era esperado naquela época. Houve certa troca de papéis nessa imagem. Aluno 02: Os índios estavam debochando da maneira como os portugueses estavam vestidos e da maneira como se comportavam. Sendo que na realidade, o que aconteceu foi o contrário, os portugueses debocharam dos índios, por andarem nus.

Aluno 03: A imagem mostra os índios debochando dos portugueses por eles estarem vestidos, mas na realidade foram os portugueses que debocharam dos índios por eles serem "selvagens" e andarem nus. Aluno 19: Nesse texto, os índios olham para os portugueses e começam a rir. Em momento algum demonstraram medo; "o papel se inverteu". Aluno 23: Nos demais textos, os portugueses é quem estão rindo e espantados com o jeito dos índios. Nesse, os índios é quem estão rindo deles. 
Etapa de pós-leitura: nessa etapa, os problemas de construção de significados em leitura apresentados pelos alunos emergiram em maior quantidade. Em específico, os alunos tiveram grande dificuldade em configurar as relaçôes passado-presente com base nos enquadramentos definidos nas perguntas, algo que pode ser discutido levando-se em conta que, durante a leitura, eles têm majoritariamente de lidar com perguntas cópia-colagem, que não suscitam articulação de significados. Porém, é interessante notar que essas relaçóes passado/presente, no fim, acabam sendo realizadas pelos alunos que responderam às perguntas, mas sem atenção à maneira como isso é pedido. Observemos, em detalhes, esse problema.

Na primeira pergunta, um dos dois critérios de comparação pedidos, a saber, a economia, foi discutido por apenas quatro alunos, dois deles transcritos abaixo:

Aluno 08: no século XVI pessoas de etnias diferentes das dos portugueses eram vistas como inferiores, o que definia o tipo de relação era a cor da pele. Hoje não se olha apenas isso, mas também o dinheiro e a classe social, sem nenhum tipo de respeito ou de admiração.

Aluno 13: Com a colonização portuguesa, se formaram classes, onde os que possuíam mais eram quem mandava. Hoje em dia ainda é assim, somos divididos em classes onde quem tem mais dinheiro é quem "pode mais".

Os demais não estabeleceram contraste, e, em sua totalidade, apresentaram afirmações acerca de como as configurações étnicas e de comunicação se dão na atualidade. Vejam-se sobre isso as duas respostas abaixo:

Aluno 18: Existem essas diferenças pela diversidade, tem branco que se sente melhor que negro, assim como rico que acha que o pobre é inferior a ele.

Aluno 20: Muitas coisas mudaram, mas o preconceito dos portugueses sobre os índios ainda continua. Atualmente, o Brasil é um país bem diversificado pela mistura de povos e culturas.

Na segunda pergunta, em que se solicitava um contraste sem critérios de comparação, os alunos tiveram um desempenho bem melhor, reconhecendo ou não coerência entre o cartum e visōes históricas atuais: 
Aluno 07: a visão de Laerte está coerente atualmente, pois sabemos que os índios foram os primeiros descobridores do Brasil, e que quando os portugueses chegaram aqui os índios já possuíam sua própria cultura. Aluno 08: Não. A maioria das pessoas ainda tem a visão parecida com a dos portugueses, de que os índios eram ignorantes e de que foram "salvos" graças aos portugueses.

Aluno 15: Não, o povo brasileiro ainda vê os indígenas daquela época como um povo discreto, receoso e não extrovertido e sociável como a charge descreve.

Na terceira pergunta, novamente com critério de comparação, as dificuldades giraram em torno de associar o contraste passado-presente à ação de apontar, que é uma informação crucial à articulação entre os textos, e não poderia ter saído de foco. Nove alunos citaram os dois textos, mas não os contrastaram de forma suficiente nem trataram da ação de apontar - vejamse duas respostas abaixo:

Aluno 07: Pero Vaz de Caminha retrata que os portugueses descobriram o Brasil e salvaram os índios da ignorância; já Laerte, que o Brasil já era ocupado pelos índios, e que eles achavam engraçados os portugueses. Aluno 21: Na visão de Caminha, os índios eram os sem cultura, o povo que devia ser colonizado, o povo que vivia pela mata como animais. Já para Laerte, os portugueses eram o povo diferente, que vivia em culturas e costumes muito diferentes, era o povo que devia aprender com os índios.

Apenas um aluno incluiu o apontar em sua resposta:

Aluno 09: Para os portugueses, o apontar era de surpresa e admiração; para Laerte, de deboche.

A discussão que pode ser feita em relação à etapa de pós-leitura da atividade diz respeito ao fato de que os problemas que os alunos apresentaram nas suas respostas não revelaram falta de capacidade cognitiva, isto é, não revelaram dificuldade em estabelecer diferentes temporalidades e falar sobre elas como dimensóes distintas, mas sim uma dificuldade metacognitiva, de realizar esse contraste de forma gerenciada, definida por critérios e 
parâmetros específicos dados previamente, como é o caso das questôes 1 e 3 , que foram aquelas em que os alunos tiveram desempenho insatisfatório.

Ora, além do fato de que só poderíamos detectar os termos em que essa dificuldade se manifesta com uma atividade com um objetivo de leitura definido, o que temos a dizer sobre isso é que essa ação gerenciada precisa ser ensinada na escola, como uma forma de refinamento da habilidade, que os alunos já têm, para comparar as coisas, e a partir de atividades como a que propusemos aos alunos, acompanhadas da discussão, junto com eles, de como elas devem ser observadas e resolvidas, e com que finalidade. Evidentemente, esse problema metacognitivo emergiu na atividade específica que ministramos, a qual solicitava que os alunos realizassem contrastes entre períodos de tempo diferentes; certamente outros problemas, e também outras capacidades, emergirão de atividades diferentes e variadas, motivadas por objetivos distintos.

\section{Sumarização e considerações finais}

Este artigo propôs-se a avaliar criticamente as atividades de leitura em livros didáticos de Português, considerando os modelos tradicionais de cópia-colagem que as estruturam, bem como a possibilidade de desenvolver atividades fundamentadas no aparato conceitual relacionado aos estudos em metacognição - no caso deste artigo, atividades fundamentadas em objetivos claros de leitura. O que justificou nossa proposta é a premissa de que atividades deste tipo permitem a realização de diagnósticos acerca das reais capacidades e dificuldades de leitura dos alunos, algo que não é possível com exercícios limitados à cópia-colagem de informações do texto.

A partir dos dados discutidos, pudemos chegar a algumas afirmações interessantes acerca dos comportamentos cognitivos dos alunos, as quais de forma alguma poderiam ser feitas com base nas tarefas dos livros didáticos:

1)Como capacidade de leitura, emergiu a possibilidade de, em um mesmo grupo, haver diferentes tomadas de perspectiva de um mesmo fato ou problema, que podem ser posteriormente partilhadas em atividades conjuntas de classe, como efeito da avaliação de leitura proporcionada pela atividade. Foi o que ocorreu na resolução da etapa durante a leitura de nossa atividade.

Houve também produção de significados para além da reprodução de informações do texto: os alunos trouxeram ideias atreladas ao tema dos 
textos que enriqueceram o seu conteúdo e que, em atividades posteriores, permitirão problematizações e intervenções críticas, com mínimo risco de fugas ao assunto central em torno do qual o objetivo da leitura dos textos foi construído.

2) Como dificuldades de leitura, emergiram dois problemas: um problema cognitivo, relacionado à formulação de inferências não autorizadas pelo material textual oferecido. Essa questão precisa estar em foco em qualquer atividade de leitura, qualquer que seja o objetivo, porque a inferência é o sinal da interferência pessoal do leitor sobre o texto, e o seu nível de qualidade está diretamente ligado à qualidade de leitura dos alunos. Além disso, é fundamental a qualquer leitor compreender quando está reproduzindo informaçôes do texto ou realizando inferências a partir dele.

E um problema metacognitivo, relacionado à articulação não gerenciada de informações, que produziu respostas insatisfatórias na fase de pós-leitura. Esse problema traz à luz a necessidade de explicitar aos alunos não apenas os objetivos da leitura, mas também os objetivos de cada atividade, ajudando-os a atentar para o que é pedido, quando se trata de apresentar informaçóes sob determinados critérios e perspectivas. Lembramos que esse é um trabalho da escola, que precisa assumir a sua responsabilidade na tarefa de construção do desenvolvimento metacognitivo das pessoas, reconhecendo a premissa de que o amadurecimento do leitor está diretamente ligado à sua capacidade de administrar da forma mais consciente possível as suas ações cognitivas no trato com o texto. O desenvolvimento das competências metacognitivas potencializará as capacidades dos alunos de construir significados mais relevantes do que a mera reprodução de informaçôes explícitas no texto, e também de discutir esse texto de forma crítica, voluntária e autonomamente interventiva.

Em termos de investigação acerca das relações entre metacognição e leitura, e em como essa propriedade humana deve ser utilizada de forma a trazer real aprendizado para os alunos em todas as Disciplinas, consideramos que este artigo relaciona-se a duas questôes de ensino mais gerais: o contexto escolar de atuação cognitiva situada, incluindo aí os objetivos das atividades didáticas, que motivam as ações cognitivas, e as formas de ação que esses objetivos suscitam. Ignorar essas questôes é praticar açôes absolutamente mergulhadas em engano e desconhecimento sobre o que elas representam 
diante de, no âmbito da escola, problemas de aprendizado, e, no âmbito da vida social, problemas de uso e saber linguístico que a escola deveria resolver.

Para a implementação de um ensino de leitura que seja de qualidade, tendo como base o desenvolvimento de uma atitude metacognitiva, é essencial que se ajudem as pessoas a gerenciar as suas propriedades de pensar e os objetivos de suas ações. O espaço da sala de aula, contexto propício para a proposição de problemas e a busca de soluções, é o lugar ideal para o desenvolvimento dessa atitude metacognitiva, que é, como vimos, um dos pré-requisitos para que os alunos adquiram autoconhecimento. E esse autoconhecimento está diretamente relacionado a reais conhecimentos.

Considerando esses desafios, este artigo pretende ser uma pequena parte de um projeto maior de pesquisa e reflexão, cujo objetivo é a proposta de reformular e desenvolver metodologias de ensino de leitura, em particular, e de línguas, em geral.

\section{Referências}

ABAURRE, M. L.; ABAURRE, M. B.; PONTARA, M. Português: contexto, interlocução e sentido - Ensino Médio. v.1, 2 e 3. São Paulo: Moderna, 2013.

APPLEGATE, M. D.; QUINN, K. B.; APPLEGATE, A. J. Levels of thinking required by comprehension questions in informal reading inventories. Reading Teacher, 56(2), 2002, p.174-180.

AMANTES, A. M.; BOTELHO, P. F.. Leitura, conhecimento prévio e ensino - uma abordagem metacognitiva. Caderno de resumos do CBLA. Rio de Janeiro: UFRJ, 2011.

BOTELHO, P. F. Textos factuais e problematizantes em livros didáticos de História: leitura e metacognição. Dissertação de Mestrado em Língua Portuguesa. Universidade Federal do Rio de Janeiro, 2010.

BRASIL. Guia de livros didáticos do PNLD - Língua portuguesa: Ensino Médio. Brasília: Secretaria de Educação Básica; Fundo Nacional para o Desenvolvimento da Educação/Ministério da Educação, 2012.

BRASIL. Matriz de Lingua Portuguesa de 3a série - Ensino Médio - Comentários sobre os Tópicos e Descritores. Brasília: INEP/Ministério da Educação, 2011. Disponível em http://provabrasil.inep.gov.br/downloads. Acessado em 10 de janeiro de 2014. CEREJA, W. R.; MAGALHĀES, T. C. Português: linguagens - literatura,produção de texto, gramática. Primeiro ano do Ensino Médio. $6^{a}$ ed. São Paulo: Atual Editora, 2010 . 
CORNOLDI, C. The impact of metacognitive reflection on cognitive control. In: Mazzoni, G.; Nelson, T. O. Ed. Metacognition and cognitive neuropsychology: control and monitoring processes. Mahwah, NJ: Lawrence Erlbaum Associates, p.139-160, 1998.

FARACO, C. E.; MOURA, F. M.; MARUXO Jr., J. H. Língua portuguesa: linguagem e interação - Ensino Médio. v.1, 2 e 3. São Paulo: Ática, 2013.

FULGÊNCIO, L.; LIBERATO, Y. Como facilitar a leitura. São Paulo: Contexto, 1992.

JOU, G.; SPERB, T. Leitura compreensiva: um estudo de caso. Linguagem e ensino, v.6, n.2, 2003, p.13-53.

KLEIMAN, A. Texto e leitor: aspectos cognitivos da leitura. Campinas: Pontes, 1995.

GEIGER, J.; MILLIS, K. Assessing the impact of reading goals and text structures on comprehension. Reading Psychology, 25, 2004, p.93-110.

GERHARDT, A. F. L. M. Uma visão sócio-cognitiva da avaliação em textos escolares. Educação e Sociedade, v.27, n.97, 2006, p.1181-1203.

GERHARDT, A. F. L. M.; ALBUQUERQUE, C.; SILVA, I. A cognição situada e o conhecimento prévio em leitura e ensino. Ciências \& Cognição, 14(2), 2009, p.74-91. ISHIWA, K.; SANJOSÉ, V.; OTERO, J. Questioning and reading goals: Information-seeking questions asked on scientific texts read under different task conditions. British Journal of Educational Psychology, 83, 2013, p.502-520.

McCLELLAND, J.; RUMELHART, D. An interactive activation model of context effects in letter perception. Part 1: an account of basic findings. Psychological Review, n.88, 1981, p.375-407.

MARCUSCHI, L. A. Compreensão de texto: algumas reflexōes. In: Dionisio, A. P. \& Bezerra, M. A. (Ed.). O livro didático de português: múltiplos olhares. Rio de Janeiro: Lucerna, p.48-61, 2001.

MENEGASSI, R. J. Compreensão e interpretação no processo de leitura: noções básicas ao professor. Revista UNIMAR, v.17, n.1, 1995, p.85-94.

NELSON, T. O.; NARENS, L. Metamemory: a theoretical framework and new findings. In: BOWER, G. (Ed.). The psychology of learning and motivation. San Diego: Academic Press, p.125-167, 1990.

NELSON, T. O.; NARENS, L. Why investigate metacognition. In: METCALFE, J. e SHIMAMURA, A. P. (Ed.). Metacognition: knowing about knowing. Cambridge: MIT Press, p.1-26, 1994.

RE, T. Reading for different goals: the interplay of EFL college students' multiple goals, reading strategy use and reading comprehension. Journal of Research in Reading, volume 31, Issue 2, 2008, p.224-242. 
SMITH, F. Compreendendo a leitura: uma análise psicolinguística da leitura e do aprender a ler. Porto Alegre: Artes Médicas, 1999 [1988].

SWAIN, K. D. CBM with Goal Setting: Impacting Students' Understanding of Reading Goals. Journal of Instructional Psychology, v.32 Issue 3, 2005, p.259-265.

TARRICONE, P. The taxonomy of metacognition. Hove: Psychology Press, 2011.

VAN DER BROEK, P.; LORCH, R.; LINDERHOLM, T.; GUSTAFSON, $M$. The effects of readers' goals on inference generation and memory for texts. Memory \& Cognition, 29 (8), 2001, p.1081-1087.

VARGAS. D. S. O plano inferencial em atividades de leitura: livro didático, cognição e ensino. Dissertação de Mestrado em Língua Portuguesa. Rio de Janeiro: UFRJ, 2012.

Data de submissão: 05/05/2014. Data de aprovação: 24/10/2014. 
